\title{
The evolution of the changes in the clinical course: a multicenter survey-related impression of the ophthalmologists at the peak of the COVID-19 pandemic in Turkey
}

\author{
Burak Erdem $(1) \cdot$ Mustafa Gok $\cdot$ Sedat Bostan
}

Received: 26 May 2020/ Accepted: 4 December 2020/Published online: 2 January 2021

(C) The Author(s), under exclusive licence to Springer Nature B.V. part of Springer Nature 2021

\begin{abstract}
Purpose The coronavirus disease-2019 (COVID-19) has become a difficult pandemic to control worldwide. The high transmission risk and mortality rates of COVID-19 cause serious concerns in ophthalmologists and may cause disruptions in clinical functioning. This study aims to identify changes in the clinical approaches of ophthalmologists, understand their anxiety levels, and exhibit how patients' follow-up processes progress during the pandemic.

Methods A questionnaire that including demographic information, ophthalmology clinical activity scale, and Beck anxiety scale was sent to ophthalmologists in Turkey. Google Forms was used as a survey platform in this study.

Results A total of 121 ophthalmologists participated in the study. The participants stated that they could not continue routine interventional diagnosis and treatment practices during the outbreak. It was clearly
\end{abstract}

\footnotetext{
B. Erdem $(\bowtie)$

Department of Ophthalmology, Ministry of Health - Ordu University Training and Research Hospital, 52200 Ordu, Turkey

e-mail: burakerdem89@gmail.com
}

M. Gok

Private Atanur Eye Hospital, 32040 Isparta, Turkey

S. Bostan

Department of Health Management, Ordu University Faculty of Health Sciences, 52200 Ordu, Turkey stated that there were changes in their clinical approach and decreased patient examination quality. For this reason, $14.9 \%$ of physicians said to missed the diagnosis in this process. Physicians who encounter infected patients state that it is more difficult to provide ophthalmological services and their clinical approaches are affected more negatively. Anxiety levels of physicians who could access personal protective equipment (PPE) and show positive solidarity with their colleagues in the process were found to be lower.

Conclusion Our study revealed that ophthalmologists, like other healthcare professionals, were severely affected by the COVID-19 outbreak. Accordingly, healthcare managers should provide adequate PPE for ophthalmologists, organize the clinical operation, and support the mental health of ophthalmologists.

Keywords COVID-19 - Ophthalmologist - Anxiety · Pandemic $\cdot$ Survey

\section{Introduction}

The coronavirus disease (COVID-19) caused by Severe Acute Respiratory Syndrome Coronavirus-2 (SARS-CoV-2) spread rapidly after emerging in Wuhan, China, in late December 2019 and became a 
difficult pandemic to control. Undoubtedly, the world's societies were not fully prepared for this devastating outbreak. Therefore, to confront this situation, nations had to make drastic decisions about preventive measures that affected every aspect of daily life.

The COVID-19 virus spreads aggressively with a higher transmissibility coefficient than the first SARSCoV-1 (3.5 and 1.5, respectively) [1]. It has been shown that transmission of COVID-19 occurs from direct contact, aerosols, and fomites, as with SARSCOV-1 [1]. The clinical picture of COVID-19 is manifested in the majority of individuals with symptoms that may include fever, cough, sore throat, fatigue, dyspnea, diarrhea, and vomiting. Moreover, the geriatric population with chronic comorbidities and immunocompromised individuals of any age can progress to acute respiratory distress syndrome (ARDS), septic shock, and mortality [2].

Difficulties in accessing personal protective equipment (PPE), increased patient density that exceeds health facilities' capacity, and work-family balance have created serious stress factors on health workers in this pandemic [3]. The world is facing a new virus with many unknowns and without a vaccine to eradicate the virus or effective treatment options at present. In the case of ophthalmologists, the nature of their routine clinical practice entails close contact with the patient both in the clinic and during interventional procedures.

In Turkey, the first COVID-19 case was reported on March 10, 2020, by the Republic of Turkey Ministry of Health [4]. As a result of 1,171,138 tests conducted as of May 4, 2020, a total of 127,659 cases had been identified, and the number of deaths recorded so far is 3461 [5]. During the global spread of the pandemic, comprehensive guidelines for the COVID-19 outbreak were prepared on February 25, with the collaboration of 26 academicians working in various institutions across the country by order of the Ministry of Health. Additionally, the Turkish Ophthalmology Society (TOD) recommended postponing elective cases and using PPE in clinical settings.

Nevertheless, ophthalmologists have continued their daily clinical activities in accordance with these precautions in private or public health institutions across the country. They are also working as active staff in regions where the outbreak is intense.

This study aimed to identify changes in the clinical approaches of ophthalmologists, assess their anxiety levels, and show how patient follow-up procedures are progressing during the pandemic.

\section{Materials and methods}

Research sample and data collection

This descriptive study surveyed 121 ophthalmology residency students, ophthalmologists, and academicians who are actively working in public and private institutions across Turkey. The data in the current survey were collected by a quantitative method. The study was carried out with the approval of the Ordu University Ethics Committee.

The questionnaire content prepared for the survey was created using Google forms. The link that provides access to the questionnaire was sent to physicians by e-mail or the WhatsApp application via digital media.

The data collection period was from April 22 to 27, 2020. During this period, 121 valid surveys were recorded.

The questionnaire used in the survey consisted of three parts: demographic information, the ophthalmology clinical activity scale, and Beck's anxiety scale.

\section{Demographic information}

Personal characteristics of the physicians, type of institution, and their position in the COVID-19 outbreak were requested and their answers to two open-ended questions.

\section{Ophthalmology clinical activity scale}

This scale was prepared by reviewing the literature and from preliminary interviews with ophthalmology clinic heads and relevant academicians working in the field to ascertain their opinions on the scope and content of the questionnaire.

\section{Beck anxiety scale}

This tool was developed by Beck et al. (1988) and adapted to the Turkish language by Ulusoy et al. (1998). The scale's reliability and validity were verified $[6,7]$. 
Because the Turkish Ophthalmology Society and the Ministry of Health had recommended postponement of frequently performed non-urgent elective surgical procedures in routine ophthalmic practice, specifying cataract, oculoplastic procedures other than trauma, adult strabismus cases, pterygium, refractive surgery, and others as examples, we defined elective cases using this list in preparing the questionnaire.

\section{Statistical analysis}

IBM SPSS for Windows (version 20.0; IBM-SPSS, Chicago, IL, USA) software was used for statistical analysis. Factor analysis was conducted to understand the construct validity of the items covered in the scales. Of a total of 20 questions in the scale, four were excluded during factor analysis because the factor loads were low or showed incompatibility. Scale validity was confirmed as 16 questions. The KaiserMeyer-Olkin (KMO) test was performed to determine the number of samples. Additionally, Bartlett's sphericity test was performed to determine the correlation significance between items and found to be significant (Chi-square approximation: 576,539, df: 120, sig: 0.000). To weigh the queries, the "principal components" method and a Varimax rotation analysis were conducted. Scale items were found to have factor loads between 0.412 and 0.841 . The scale with 15 queries was collected under three factors: deterioration in ophthalmological services (five expressions), changes in clinical approaches (six expressions), and assessment of combatting the COVID-19 outbreak and preventive measures(four expressions). The variance description level of the factors that constitute the scale was calculated as $48.6 \%$. The Beck anxiety scale was validated by factor analysis. For the reliability analysis of the survey, Cronbach's alpha coefficient was performed and found reliable (0.831). Finally, evaluating participants' clinical behaviors according to their demographic and other characteristics was conducted using a $t$-test and ANOVA.

\section{Results}

Demographic data of 121 ophthalmologists participating in the study are presented in Table 1 . Of these participants, $68.6 \%$ encountered patients infected with
SARS-CoV-2; $65.3 \%$ were actively involved in the treatment of infected patients; $18.2 \%$ had been tested for COVID-19; and two had received a positive result.

To understand how ophthalmology clinics continue their activities during the pandemic, Table 2 presents the findings of this survey, which was conducted on a five-point Likert scale and evaluated on the basis of three factors.

The results reflect that most routine patient examinations $(3.42 \pm 1.30)$ and routine diagnostic and interventional applications $(4.11 \pm 1.22)$ could not be continued; elective surgery cases (cataract, oculoplastic procedures other than trauma, adult strabismus cases, pterygium, refractive surgery, etc.) $(4.67 \pm 0.80)$ were postponed; patients usually did not come in for routine control $(3.95 \pm 0.94)$, and follow-up visits were seriously disrupted $(3.88 \pm 1.05)$.

In terms of the clinical approach with patients, the ophthalmologists stated that the time allocated to the patient for examination $(3.38 \pm 1.39)$, the time spent at the biomicroscope $(3.86 \pm 1.24)$, and patient examination quality $(3.59 \pm 1.32)$ were significantly reduced.

Survey responses revealed that telemedicine techniques $(4.23 \pm 1.14)$ were not used for patient followup, and clinical scientific meetings and seminars $(4.48 \pm 1.01)$ could not be organized.

The ophthalmologists stated that they had not experienced above average problems obtaining PPE $(3.45 \pm 1.46)$, and they had sensed positive solidarity with their colleagues during the pandemic $(3.91 \pm 1.11)$.

The effectiveness and success of the national health system $(4.0 \pm 1.08)$ and efforts to combat the pandemic $(3.76 \pm 1.08)$ were viewed favorably by the participants.

Ophthalmologists' anxiety levels as assessed by Beck's anxiety scale are given in Table 3. It revealed that $17.3 \%$ of ophthalmologists had mild anxiety, $7.6 \%$ had moderate, and $11.5 \%$ had severe anxiety.

In an open-ended question, "Has the number of patients admitted to your clinic with ophthalmological emergency complaints decreased during the COVID19 pandemic?", $88.6 \%$ of respondents answered in the affirmative. They attributed this to the fear people have of applying to the hospital-the only admissions were true emergencies-and a reduction in out-ofhome traumas due to the quarantine. Additionally, 
Table 1 Demographic data of the participants

\begin{tabular}{|c|c|c|}
\hline Variable & $N$ & $\%$ \\
\hline \multicolumn{3}{|l|}{ 1.Gender } \\
\hline Female & 46 & 38 \\
\hline Male & 75 & 62 \\
\hline \multicolumn{3}{|l|}{ 2.Age } \\
\hline 39 and below & 74 & 61.2 \\
\hline $40-49$ & 35 & 28.9 \\
\hline $50-59$ & 12 & 9.9 \\
\hline \multicolumn{3}{|l|}{ 3.Working year as an ophthalmologist } \\
\hline $1-5$ years & 27 & 21.7 \\
\hline $6-10$ years & 42 & 35.0 \\
\hline $11-15$ years & 21 & 17.5 \\
\hline 16 and up & 31 & 25.8 \\
\hline \multicolumn{3}{|l|}{ 4.Institution } \\
\hline State hospital & 68 & 57.6 \\
\hline University hospital & 27 & 22.0 \\
\hline Private hospital & 26 & 20.3 \\
\hline \multicolumn{3}{|l|}{ 5. Title } \\
\hline Ophthalmology residency & 15 & 12.4 \\
\hline Ophthalmology specialist & 77 & 63.6 \\
\hline Academician (Professor, Associate Professor) & 29 & 24.0 \\
\hline \multicolumn{3}{|l|}{ 6. Is your hospital a pandemic hospital? } \\
\hline Yes & 90 & 74.4 \\
\hline No & 19 & 15.7 \\
\hline Not a pandemic hospital, but there are COVID-19 patients & 12 & 9.9 \\
\hline \multicolumn{3}{|l|}{ 7. Have you ever encountered COVID-19 patients? } \\
\hline Yes & 83 & 68.6 \\
\hline No & 38 & 31.4 \\
\hline \multicolumn{3}{|l|}{ 8. Did you serve COVID-19 patients? } \\
\hline Yes & 79 & 65.3 \\
\hline No & 42 & 34.7 \\
\hline \multicolumn{3}{|l|}{ 9. Have you had the COVID 19 test? } \\
\hline Yes & 22 & 18.2 \\
\hline No & 99 & 81.8 \\
\hline \multicolumn{3}{|l|}{ 10. If you have had COVID 19 test, Result? } \\
\hline Positive & 2 & 9.1 \\
\hline Negative & 20 & 90.9 \\
\hline \multicolumn{3}{|l|}{ 11. If you have the disease, your condition? } \\
\hline \multicolumn{3}{|l|}{ I spend without symptoms, I'm quarantine } \\
\hline \multicolumn{3}{|l|}{ I am receiving a hospitalized treatment } \\
\hline I'm healed & 2 & 100 \\
\hline
\end{tabular}

$14.9 \%$ of physicians answered yes to the other openended question, "Have you missed a diagnosis during the pandemic?".
In our study, female specialists were more likely than males to state that routine ophthalmological services were further impaired $(P=0.012)$. Female specialists were also found to have higher anxiety 
Table 2 Frequency distribution of ophthalmology clinical activity scale

\begin{tabular}{|c|c|c|c|c|c|c|c|c|c|c|c|c|}
\hline \multirow[t]{3}{*}{ Expressions } & \multicolumn{10}{|c|}{$\begin{array}{l}\text { Investigation of the Effect of COVID-19 Pandemic on } \\
\text { Ophthalmology Clinic Activities }\end{array}$} & \multirow[t]{3}{*}{ Mean } & \multirow[t]{3}{*}{ SD } \\
\hline & \multicolumn{2}{|c|}{$\begin{array}{l}\text { I don't } \\
\text { agree at } \\
\text { all }\end{array}$} & \multicolumn{2}{|c|}{$\begin{array}{l}\text { I } \\
\text { disagree }\end{array}$} & \multicolumn{2}{|c|}{$\begin{array}{l}\text { I } \\
\text { partially } \\
\text { agree }\end{array}$} & \multicolumn{2}{|c|}{ Agree } & \multicolumn{2}{|c|}{$\begin{array}{l}\text { I totally } \\
\text { agree }\end{array}$} & & \\
\hline & $N$ & $\%$ & $N$ & $\%$ & $N$ & $\%$ & $N$ & $\%$ & $N$ & $\%$ & & \\
\hline Deterioration in ophthalmological services & & & & & & & & & & & 4.00 & 0.71 \\
\hline We cannot continue routine patient admission & 15 & 12.4 & 14 & 11.6 & 26 & 21.5 & 37 & 30.6 & 29 & 24 & 3.42 & 1.30 \\
\hline $\begin{array}{l}\text { We cannot continue our routine interventional diagnostic } \\
\text { and treatment practice }\end{array}$ & 9 & 7.4 & 5 & 4.1 & 15 & 12.4 & 26 & 21.5 & 66 & 54.5 & 4.11 & 1.22 \\
\hline $\begin{array}{l}\text { We postpone the operations of elective cases. (cataract, } \\
\text { oculoplastic procedures other than trauma, adult } \\
\text { strabismus cases, pterygium, refractive surgery, etc.) }\end{array}$ & 2 & 1.7 & 3 & 2.5 & 5 & 4.1 & 12 & 9.9 & 99 & 81.9 & 4.67 & 0.80 \\
\hline $\begin{array}{l}\text { Patients requiring routine follow-ups before pandemic } \\
\text { (surgery, intravitreal inj., etc.) do not come to routine } \\
\text { visits }\end{array}$ & 3 & 2.5 & 4 & 3.3 & 27 & 22.3 & 49 & 40.5 & 38 & 31.4 & 3.95 & 0.94 \\
\hline $\begin{array}{l}\text { Patients requiring routine follow-ups before pandemic } \\
\text { (surgery, intravitreal inj. etc.) are experiencing serious } \\
\text { failure in the follow-up process }\end{array}$ & 5 & 4.1 & 4 & 3.3 & 33 & 27.3 & 37 & 30.6 & 42 & 34.7 & 3.88 & 1.05 \\
\hline Changes in clinical approach & & & & & & & & & & & 3.83 & 0.88 \\
\hline The examination time decreased & 19 & 15.7 & 11 & 9.1 & 30 & 24.8 & 26 & 21.5 & 35 & 28.9 & 3.38 & 1.39 \\
\hline The time of the biomicroscopic examination decreased & 8 & 6.6 & 11 & 9.1 & 21 & 17.4 & 30 & 24.8 & 51 & 42.1 & 3.86 & 1.24 \\
\hline I think the quality of the patient examination was reduced & 15 & 12.4 & 7 & 5.8 & 29 & 24.0 & 31 & 25.6 & 39 & 32.2 & 3.59 & 1.32 \\
\hline $\begin{array}{l}\text { I think that the quality of my interventional procedures } \\
\text { (surgery/intravitreal inj./laser etc.) was reduced }\end{array}$ & 24 & 19.8 & 10 & 8.3 & 20 & 16.5 & 21 & 17.4 & 46 & 38.0 & 3.45 & 1.54 \\
\hline $\begin{array}{l}\text { We do not use telemedicine techniques in the follow-up } \\
\text { processes of patients requiring routine control before } \\
\text { pandemic (surgery, intravitreal inj., etc.) }\end{array}$ & 5 & 4.1 & 7 & 5.8 & 17 & 14.0 & 17 & 14.0 & 75 & 62.0 & 4.23 & 1.14 \\
\hline $\begin{array}{l}\text { We are unable to perform our in-clinical scientific } \\
\text { meeting-seminar programs }\end{array}$ & 4 & 3.3 & 4 & 3.3 & 11 & 9.1 & 12 & 9.9 & 90 & 74.4 & 4.48 & 1.01 \\
\hline $\begin{array}{l}\text { Qualification in fighting with COVID-19 outbreak and } \\
\text { preventive measures }\end{array}$ & & & & & & & & & & & 3.78 & 0.67 \\
\hline $\begin{array}{l}\text { I do not have any shortage of personal protective } \\
\text { equipment in the clinic }\end{array}$ & 18 & 14.9 & 17 & 14.0 & 20 & 16.5 & 24 & 19.8 & 42 & 34.7 & 3.45 & 1.46 \\
\hline $\begin{array}{l}\text { I think we are in positive solidarity with our colleagues } \\
\text { during the pandemic process }\end{array}$ & 3 & 2.5 & 12 & 9.9 & 26 & 21.5 & 31 & 25.6 & 49 & 40.5 & 3.91 & 1.11 \\
\hline $\begin{array}{l}\text { I think we have been successful as a health system in the } \\
\text { fight against pandemics }\end{array}$ & 4 & 3.3 & 8 & 6.6 & 22 & 18.2 & 36 & 29.8 & 51 & 42.1 & 4.00 & 1.08 \\
\hline $\begin{array}{l}\text { I think we have succeeded as a country in the fight against } \\
\text { pandemic }\end{array}$ & 6 & 5.0 & 8 & 6.6 & 29 & 24.0 & 44 & 36.4 & 34 & 28.1 & 3.76 & 1.08 \\
\hline
\end{tabular}

$S D$ Standard deviation

levels than their male counterparts $(P=0.018)$. Considering the age factor, physicians aged $40-49$ stated that they performed more non-routine procedures compared to those aged 50 and over $(P=0.045)$. Also, physicians aged 39 and under reported more unfavorable changes in their clinical approaches than did those aged 50 and over $(P=0.024)$.

In terms of length of time working, the 1-5-year employees stated worse changes in their clinical 
Table 3 Evaluation of beck anxiety scales of ophthalmologists

\begin{tabular}{lll}
\hline Back anxiety scale & $N$ & $\%$ \\
\hline No & 77 & 63.6 \\
Mild & 21 & 17.3 \\
Moderate & 9 & 7.6 \\
Severe & 14 & 11.5 \\
\hline
\end{tabular}

approach than those of 16 years of work or more $(P=0.035)$.

As to the type of institution, physicians working at state hospitals reported more deterioration in ophthalmological services than physicians working in private hospitals $(P=0.006)$. The impairment in clinical approaches differed for each type $(P=0.001)$. Clinical approaches of resident ophthalmologists were found to be more negatively affected than those of academicians $(P=0.005)$. Ophthalmologists stated that the clinical course in pandemic hospitals was more disrupted $(P=0.001)$.

Physicians encountering COVID-19 patients reported greater impairment $(P=0.019)$ in ophthalmological services and in their clinical approaches than those who had not encountered them $(P=0.001)$. Similarly, the clinical approach of physicians serving patients with COVID-19 showed more negative changes than those who did not $(P=0.001)$.

With regard to the question, "Have you missed a diagnosis in the pandemic process?", it was observed that the clinical approach of physicians who said "yes" to the question was affected more negatively than others $(P=0.001)$.

Possible relationships between the items on the ophthalmology clinical activity scale and the Beck anxiety scale were investigated using a Pearson correlation analysis. These data are presented in Table 4.

Thus, deterioration in ophthalmological services also worsened clinical approaches $(P=0.001)$. In addition, an increase in physicians' anxiety scores affected their clinical approaches $(P=0.001)$. Treatment success and qualification of the preventive measures were factors that led to a decrease in physicians' anxiety values $(P=0.001)$.

\section{Discussion}

The COVID-19 outbreak caused significant anxiety and mental health problems in healthcare workers [8]. Ophthalmologists feel more at risk compared to other specialists because they have to be in close contact with patients [9]. On February 7, 2020, the death of ophthalmologist Dr. Li Wenliang from COVID-19 in Wuhan, China, may be one of the reasons contributing to this concern. In the first days of the pandemic, Dr. Li warned his colleagues about the potential of a novel atypical infection and called on his colleagues to use PPE [10].

Recent studies provide evidence of the transmission of the SARS-CoV-2 virus by ocular surface contact [11]. In a large clinical trial, the incidence of conjunctivitis in COVID-19 cases was reported to be greater that $1.0 \%$ [12]. We cannot provide precise information about the conjunctivitis incidence in COVID-19 patients due to the lack of ophthalmological examinations at the time of diagnosis [13], but conjunctivitis can occasionally be the only symptom of COVID-19 [14]. Considering these data, ophthalmologists may encounter potential COVID-19 patients more often in the clinic than they expected [15].

In our study, it was observed that ophthalmologists reported a significant deterioration in their ophthalmological services and could not continue their routine interventional, diagnostic, and treatment practice. In addition to restrictions to daily life during the pandemic, some countries have also restricted outpatient services, elective surgery, and interventional procedures to reduce the risk of transmission in hospitals. During the pandemic, precautions in clinical settings were required to minimize the transmission of the infection and to provide effective care for eye emergency cases and patients who required periodic follow-up. Global collaboration is needed with regard to these preventive measures and scientific data for risk reduction actions to be taken in case of a possible future pandemic [16].

In our study, $82.6 \%$ of ophthalmologists stated that the number of patients admitted to the clinic with ophthalmological emergency complaints decreased. This is attributed to patients' fear of getting infected in hospitals. Also, these data confirmed changes in patients' attitudes about emergency complaints during the pandemic. Participants stated that they generally 
Table 4 Ophthalmology clinical activity scale factors and beck anxiety scale correlation analysis

\begin{tabular}{llll}
\hline & $\begin{array}{l}\text { Deterioration in } \\
\text { ophthalmological } \\
\text { services }\end{array}$ & $\begin{array}{l}\text { Changes in } \\
\text { clinical } \\
\text { approach }\end{array}$ & $\begin{array}{l}\text { Qualification in fighting with } \\
\text { COVID-19 outbreak and preventive } \\
\text { measures }\end{array}$ \\
\hline $\begin{array}{l}\text { Deterioration in ophthalmological } \\
\text { services }\end{array}$ & 1 & $\begin{array}{l}\text { Beck } \\
\text { anxiety } \\
\text { scale data }\end{array}$ \\
$\begin{array}{l}\text { Changes in clinical approach } \\
\begin{array}{l}\text { Qualification in fighting with } \\
\text { COVID-19 outbreak and preventive } \\
\text { measures }\end{array}\end{array}$ & $.270(* *)$ & 1 & 1 \\
Beck anxiety scale data & .178 & -.047 & \\
\hline
\end{tabular}

Pearson correlation analyses. $* *$ Correlation is significant at the 0.01 level (2-tailed)

did not use telemedicine alternatives for patient follow-up. Perhaps, more widespread use of telemedicine options would have led to admission of emergency cases more often than the survey results reported. While observing strict social isolation conditions during the pandemic, a video interview between the ophthalmologist and the patient may indicate whether there is an urgent need for medical care [17]. In a medical examination in France via telemedicine, a patient was first diagnosed with conjunctivitis, but the patient's subsequent cough and dyspnea complaints prompted the doctor to advise a hospital visit which resulted in a diagnosis of COVID-19 [18]. In this respect, telemedicine contact was very useful. It is likely that virtual triages, which can be done with artificial intelligence, will be on the agenda in a possible future outbreak [19].

At a certain point after the outbreak of the pandemic, by decision of the Ministry of Health, state hospitals were declared pandemic hospitals to meet the increasing patient density and the need for intensive care. Physicians in these hospitals, including ophthalmologists, were commissioned as active staff in the care of COVID-19 patients at every stage. Ophthalmologists working in branch hospitals (eye centers) were not affected by this decision. Therefore, there has been a more pronounced disruption in the quality and availability of services provided to eye patients in state hospitals.

It was clearly stated by the participants in this study that there were also changes in clinical approaches and a marked decrease in patient examination quality during the pandemic. Physicians encountering patients with COVID-19 reported that it was more difficult to provide routine ophthalmological examinations, care, and the performance of clinical approaches. It is also noteworthy that one of the most critical questions of the survey, "Did you miss a diagnosis related to the pandemic process?", was responded affirmatively by $14.9 \%$ of the physicians. Those who said yes to this question concluded that there was a significant reduction in their examination quality and the time allocated to each patient in the course of clinical practice $(P=0.001)$. These data show that physicians who are afraid of being exposed to aerosols of patients are more likely to make a misdiagnosis in a slit-lamp examination. This is problematic for diagnostic and treatment procedures. At this point, health administrators must provide adequate PPE for ophthalmologists in the clinic and organize an optimal clinical schedule. Additionally, we suggest that remote-controlled diagnosis, treatment, and imaging methods should be developed by biomedical engineers so that ophthalmologists can continue their normal routine despite an outbreak that may occur again in the future. We may experience new robotic surgery developments after this period [20].

According to the Beck anxiety scale data in our study, $17.3 \%$ of physicians had mild, $7.6 \%$ moderate, and $11.5 \%$ severe anxiety levels. These levels among physicians with ready access to PPE and a positive sense of solidarity with their colleagues were lower. Organizers of health management should proactively provide mental health support to ophthalmologists as well as other healthcare professionals. In other words, support processes should be started before employees' mental health begins to react to altered circumstances [8]. In addition, healthcare administrators providing 
sufficient PPE and equipment for ophthalmologists will reduce their anxiety and promote a positive change in their clinical approach during the COVID19 or any other outbreak.

The majority of our participants stated that they found the health organization $(4.0 \pm 1.08)$ and the fight against the pandemic (3.76 \pm 1.08$)$ successful in the country. Despite the increasing burden on healthcare professionals, many factors play a role in ophthalmologists' satisfaction with the health organization. In January 2020, before the declaration of a pandemic by the World Health Organization in March 2020, Turkey's Ministry of Health had decided to create a scientific committee consisting of academicians who are experts in their fields [21]. Rapid adoption of precautions recommended by the scientific committee may have reduced the burden on the health system and healthcare professionals. We think this may be one of the reasons for ophthalmologists' positive feedback.

Additionally, these ophthalmologists stated that they did not encounter greater than normal difficulty accessing PPE $(3.45 \pm 1.46)$, in contrast to many countries of the world who did have trouble with this issue. This is another factor that may have affected the ophthalmologists' responses.

This study has certain limitations. Unfortunately, it was not possible to reach the majority of Turkish ophthalmologists in this study, possibly because the ophthalmologists felt the questionnaire was too long. In addition, in the period of this study, there were already ongoing dynamic processes and accordingly, the opinions of physicians may have been changing. In future studies, asking participants more specific questions about diabetic retinopathy and neovascular AMD patients who received intravitreal injections could add value to the study; we opted not to add such questions in the interest of keeping the survey brief.

In conclusion, recognizing that our world is always susceptible to pandemic disease, we as ophthalmologists should be preparing for the next outbreak. There is a need for a global collaborative studies on precautions to be taken to maintain effective clinical care for patients with ophthalmological disorders without jeopardizing the safety of patients or physicians.

These survey results showed that ophthalmologists are a group of physicians who were severely affected by this troubling pandemic experience. Health institutions and organizers should routinely provide the necessary attention to the mental health of their employees and ophthalmologists and to support them not only in their working environment but also in their personal lives [22].

Acknowledgements The authors thank all the participants who selflessly collaborated in this research

Author contributions Burak Erdem contributed to material preparation, data collection, and wrote manuscript. Mustafa Gök collected data and prepared a study draft. Sedat Bostan contributed to material preparation and data analysis. All authors have read and approved the final version of the manuscript.

Funding Authors have no financial or proprietary interest in any product mentioned in the article. No funding was received for this research.

\section{Compliance with ethical standards}

Conflict of interest No author has any possible conflict of interest. The authors alone are responsible for the content and preparation of the paper.

Ethical approval All the procedures were done in accordance with the ethical standards of the Ordu University Ethics Committee and the 1964 Helsinki Declaration. The survey was sent to ophthalmologists after it is approved by ethical committee.

Informed consent Online informed consent was obtained from all individual participants included in the study.

\section{References}

1. Li Q, Guan X, Wu P, Wang X, Zhou L, Tong Y, Ren R, Leung KSM, Lau EHY et al (2020) Early transmission dynamics in Wuhan, China, of novel coronavirus-infected pneumonia. N Engl J Med 382(13):1199-1207. https://doi.org/10.1056/NEJMoa2001316

2. Lai CC, Shih TP, Ko WC, Tang HJ, Hsueh PR (2020) Severe acute respiratory syndrome coronavirus 2 (SARSCoV-2) and coronavirus disease-2019 (COVID-19): the epidemic and the challenges. Int $\mathrm{J}$ Antimicrob Agents 55(3):105924. https://doi.org/10.1016/j.ijantimicag.2020. 105924

3. Greenberg N, Docherty M, Gnanapragasam S, Wessely S (2020) Managing mental health challenges faced by healthcare workers during covid-19 pandemic. BMJ 26(368):m1211. https://doi.org/10.1136/bmj.m1211

4. Şahin M (2020) Impact of weather on COVID-19 pandemic in Turkey. Sci Total Environ 20(728):138810. https://doi. org/10.1016/j.scitotenv.2020.138810

5. Available from: https://www.worldometers.info/ coronavirus/ [Accessed on May 4, 2020] 
6. Beck AT, Epstein N, Brown G, Steer RA (1988) An inventory for measuring clinical anxiety: psychometric properties. J Consult Clin Psychol 56:893-897. https://doi. org/10.1037//0022-006x.56.6.893

7. Ulusoy M, Sahin NH, Erkmen H (1998) Turkish version of the Beck Anxiety Inventory: psychometric properties. J Cogn Psychother 12:163-172

8. Walton M, Murray E, Christian MD (2020) Mental health care for medical staff and affiliated healthcare workers during the COVID-19 pandemic. Eur Heart J Acute Cardivasc Care 28:2048872620922795. https://doi.org/10.1177/ 2048872620922795

9. Nair AG, Gandhi RA, Natarajan S (2020) Effect of COVID19 related lockdown on ophthalmic practice and patient care in India: results of a survey. Indian $\mathrm{J}$ Ophthalmol 68(5):725-730. https://doi.org/10.4103/ijo.IJO_797_20

10. Parrish RK, Stewart MW, Duncan Powers SL (2020) Ophthalmologists are more than eye doctors-in memoriam $\mathrm{Li}$ Wenliang. Am J Ophthalmol. https://doi.org/10.1016/j.ajo. 2020.02.014

11. Lu CW, Liu XF, Jia ZF (2020) 2019-nCoV transmission through the ocular surface must not be ignored. Lancet 395(10224):e39. https://doi.org/10.1016/S01406736(20)30313-5

12. Guan WJ, Ni ZY, Hu Y, Liang WH, Ou CQ, He JX, Liu L, Shan H, Lei CL, Hui DSC et al (2020) Clinical Characteristics of coronavirus disease 2019 in China. N Engl J Med 382(18):1708-1720. https://doi.org/10.1056/ NEJMoa2002032

13. Guo D, Xia J, Shen Y, Tong J (2020) SARS-CoV-2 may be related to conjunctivitis but not necessarily spread through the conjunctiva SARS-CoV-2 and conjunctiva. J Med Virol. https://doi.org/10.1002/jmv.25856

14. Wu P, Liang L, Chen C, Nie S (2020) A child confirmed COVID-19 with only symptoms of conjunctivitis and eyelid dermatitis. Graefes Arch Clin Exp Ophthalmol. https://doi. org/10.1007/s00417-020-04708-6

15. Chodosh J. Alert: important coronavirus updates for ophthalmologists. (2020) American academy of ophthalmology
URL: https://www.aao.org/headline/alert-importantcoronavirus-context [Accessed May 6, 2020]

16. Olivia Li JP, Shantha J, Wong TY, Wong EY, Mehta J, Lin H, Lin X, Strouthidis NG, Park KH, Fung AT et al (2020) Preparedness among ophthalmologists: during and beyond the COVID-19 pandemic. Ophthalmology 127(5):569-572. https://doi.org/10.1016/j.ophtha.2020.03.037

17. Tang RA, Morales M, Ricur G, Schiffman JS (2005) Telemedicine for eye care. J Telemed Telecare 11:391-396. https://doi.org/10.1177/1357633X0501100803

18. Daruich A, Martin D, Bremond-Gignac D (2020) Ocular manifestation as first sign of coronavirus disease 2019 (COVID-19): interest of telemedicine during the pandemic context. J Fr Ophtalmol. https://doi.org/10.1016/j.jfo.2020. 04.002

19. Hollander JE, Carr BG (2020) Virtually perfect? telemedicine for COVID-19. N Engl J Med 382(18):1679-1681. https://doi.org/10.1056/ NEJMp2003539

20. Kimmig R, Verheijen RHM, Rudnicki M (2020) Robot assisted surgery during the COVID-19 pandemic, especially for gynecological cancer: a statement of the society of european robotic gynaecological surgery (SERGS).

J Gynecol Oncol 31(3):e59. https://doi.org/10.3802/jgo. 2020.31.e59

21. Demirbilek Y, Pehlivantürk G, Özgüler ZÖ, Alp Meşe E (2020) COVID-19 outbreak control, example of ministry of health of Turkey. Turk J Med Sci 21(50):489-494. https:// doi.org/10.3906/sag-2004-187

22. Zhang C, Yang L, Liu S (2020) Survey of insomnia and related social psychological factors among medical staff involved in the 2019 novel coronavirus disease outbreak. Front Psychiatry 14(11):306. https://doi.org/10.3389/fpsyt. 2020.00306

Publisher's Note Springer Nature remains neutral with regard to jurisdictional claims in published maps and institutional affiliations. 